\title{
Deguelin, a natural rotenoid, inhibits mouse myeloma cell growth in vitro via induction of apoptosis
}

\author{
ZHENGGUANG LI, JUN WU, CHANGPING WU, JINGTING JIANG, XIAO ZHENG, BIN XU and MIN LI \\ Department of Oncology, The Third Affiliated Hospital of Soochow University, Changzhou 213003, P.R. China
}

Received March 22, 2012; Accepted June 29, 2012

DOI: $10.3892 / \mathrm{ol} .2012 .790$

\begin{abstract}
Deguelin is a naturally occurring rotenoid with strong cancer chemopreventive and antitumor activities. In the present study, we investigated the antitumor activity of deguelin against MPC-11 murine myeloma cells and the possible mechanism of action in vitro. Our results revealed that deguelin inhibited the proliferation of MPC-11 cells in a concentration- and time-dependent manner and caused the apoptotic death of MPC-11 cells. Following exposure to deguelin, the phosphorylation of Akt was decreased. The inhibition of cell growth may be associated with decreased levels of phosphorylated Akt. Deguelin-induced apoptosis was characterized by the upregulation of Bax, downregulation of Bcl-2 and activation of caspase-3. In conclusion, deguelin inhibits murine myeloma cell proliferation by inducing apoptosis via regulation of the $\mathrm{Bax} / \mathrm{Bcl}-2$ ratio and by inhibition of the activation of Akt. Its potential as an anticancer agent against multiple myeloma warrants further investigation.
\end{abstract}

\section{Introduction}

Multiple myeloma is a neoplastic plasma cell disorder that is characterized by the clonal proliferation of malignant plasma cells in the bone marrow microenvironment, monoclonal protein in the blood or urine and associated organ dysfunction. Worldwide, it is estimated that approximately 86,000 cases of multiple myeloma occur annually, accounting for approximately $0.8 \%$ of all new cancer cases. Approximately 63,000 individuals are reported to succumb to the disease each year, accounting for $0.9 \%$ of all cancer mortalities and $13 \%$ of all mortalities due to hematological cancers. In recent years, the introduction of autologous stem-cell transplantation and the availability of agents such as thalidomide, lenalidomide and bortezomib have changed the management of myeloma and

Correspondence to: $\mathrm{Dr}$ Zhengguang $\mathrm{Li}$, Department of Oncology, The Third Affiliated Hospital of Soochow University, No. 185 Juqian Sreet, Tianning Zone, Changzhou 213003, P.R. China E-mail:1zg1029@gmail.com

Key words: deguelin, multiple myeloma, apoptosis extended overall survival. However, the treatment outcome is far from satisfactory and novel drugs are in urgent demand to more effectively treat this malignancy $(1,2)$.

It is well known that numerous natural compounds, especially plant products, have been found to exhibit anticancer effects and that some play important roles in cancer treatment. Rotenoids, which are typically insecticidal agents, constitute a class of compounds from the flavonoid family and have cancer chemopreventive and anticancer activities $(3,4)$. Deguelin is a natural rotenoid which has been isolated from several plant species, including Mundulea sericea (Leguminosae; Fig. 1). Recently, deguelin has been found to exhibit strong cancer chemopreventive and antitumor activities in vitro and in vivo in various model systems (2-9). However, the antitumor effects of deguelin against multiple myeloma have not been reported.

In the present study, we investigated the antitumor effect of deguelin against multiple myeloma cells and the mechanism by which it occurs. Using murine myeloma MPC-11 cells, we demonstrated that deguelin exhibits antitumor activity on the cells by inhibiting the activity of the Akt pathway and inducing apoptosis. Our study suggests that deguelin is a potential agent to combat multiple myeloma.

\section{Materials and methods}

Materials. 3-(4,5)-dimethylthiazol(-z-y1)-3,5-diphenyltetrazolium bromide (MTT), dimethyl sulfoxide (DMSO), RNase A and propidium iodide (PI) were purchased from Sigma Chemical Co. (St. Louis, MO, USA). The total protein extraction kit was purchased from Keygen Co. (Nanjing, China). All the chemicals employed in this study were analytically pure and of culture grade. The primary antibodies for Akt/p-Akt, Bcl-2 and Bax were purchased from Cell Signaling Technology (Beverly, MA, USA) and cleaved caspase-3 antibody was purchased from Beyotime Co. (Hangzhou, China). The protein assay kit was purchased from Bio-Rad (Hercules, CA, USA).

Deguelin was purchased from Sigma Chemical Co., dissolved in DMSO as a stock solution, then stored at $4^{\circ} \mathrm{C}$. Prior to experiments, the stock solution was diluted in cell culture medium at a final DMSO concentration of $0.05 \%(\mathrm{~V} / \mathrm{V})$.

Cell culture. The murine myeloma MPC-11 cell line was obtained from the American Type Culture Collection (ATCC, Manassas, VA, USA). The cells were grown in RPMI-1640 
medium (Life Technologies, Bedford, MA, USA) containing $10 \%$ heat-inactivated fetal bovine serum, $100 \mathrm{U} / \mathrm{ml}$ penicillin and $100 \mathrm{U} / \mathrm{ml}$ streptomycin in a humidified chamber at $37^{\circ} \mathrm{C}$ with a $5 \% \mathrm{CO}_{2}$ atmosphere.

Cell viability assay. The cell viability of the deguelin-treated cancer cells was determined using the MTT assay. Briefly, the cells $\left(4-5 \times 10^{3}\right)$ were seeded in 96-well plates and cultured for $24 \mathrm{~h}$, followed by deguelin treatment for 24,48 or $72 \mathrm{~h}$. A volume of $10 \mu \mathrm{l}$ of $10 \mathrm{mg} / \mathrm{ml}$ MTT was added per well and the cells were incubated for another $4 \mathrm{~h}$ at $37^{\circ} \mathrm{C}$. The plates were then centrifuged at $1,000 \mathrm{x} \mathrm{g}$ for $10 \mathrm{~min}$, the supernatant fluid was removed and DMSO was added, $150 \mu \mathrm{l} /$ well for 15-20 min. The light absorptions (OD) were measured at $570 \mathrm{~nm}$ with SpectraMAX M5 microplate spectrophotometer (Molecular Devices, Sunnyvale, CA, USA). All experiments were performed in triplicate. The effect of deguelin on the proliferation of cells was expressed as the cell growth inhibition, using the following formula: inhibition rate $=(\mathrm{A} 570$ of control - A570 of treated cells)/A570 of control cells x 100\%.

Agarose gel DNA electrophoresis. In order to clarify whether the inhibitory effect of the deguelin on MPC-11 cells was due to apoptosis, the pattern of DNA cleavage was analyzed by agarose gel electrophoresis as described previously $(10,11)$. Briefly, following treatment with deguelin, the cells $\left(3 \times 10^{6}\right)$ were lysed with $0.5 \mathrm{ml}$ lysis buffer (5 mM Tris-HCL (pH 8.0), $0.25 \%$ Nonidet P40 and $1 \mathrm{mM}$ EDTA), followed by the addition of RNase A (Sigma) at a final concentration of $200 \mu \mathrm{g} / \mathrm{ml}$. Following incubation for $1 \mathrm{~h}$ at $37^{\circ} \mathrm{C}$, the cells were treated with $300 \mu \mathrm{g} / \mathrm{ml}$ proteinase $\mathrm{K}$ for an additional hour at $37^{\circ} \mathrm{C}$. A volume of $20 \mu \mathrm{l}$ of sample in each lane was subjected to electrophoresis on a $1.5 \%$ agarose at $50 \mathrm{~V}$ for $3 \mathrm{~h}$. DNA was stained with ethidium bromide.

Morphological analysis. Following culture and drug treatment as described above, the morphological changes of the cells were observed. The cells were fixed using $70 \%$ ethanol following rinsing with PBS. After examination for morphological changes with an inverted microscope, the cells were stained with PI ( $1 \mu \mathrm{g} / \mathrm{ml}$ in PBS) and analyzed under a fluorescence microscope (Zeiss, Axiovert 200, Göttingen, Germany) to identify the apoptotic cells.

Western blot analysis. To identify the mechanisms of proliferation inhibition and apoptosis induction of deguelin, an immunoblot analysis was performed. Briefly, $5 \times 10^{6}$ cells were lysed in $1 \mathrm{ml}$ lysis buffer and the protein concentration was determined using the Bio-Rad protein assay reagent. The samples were denatured in sample buffer and the proteins were separated by sodium dodecyl sulfate-polyacrylamide gel electrophoresis. The gels were electroblotted onto a polyvinylidene difluoride membrane. The membrane blots were rinsed with TBS/T (20 mM Tris, 500 mM NaCl, 0.1\% Tween-20, pH 7.6) and blocked with $5 \%$ non-fat dry milk in blocking buffer. The membrane was incubated with the desired primary antibody overnight at $4^{\circ} \mathrm{C}$. The membrane was then incubated with the appropriate peroxidase-conjugated secondary antibody and the immunoreactive bands were visualized using the enhanced chemiluminescence method.

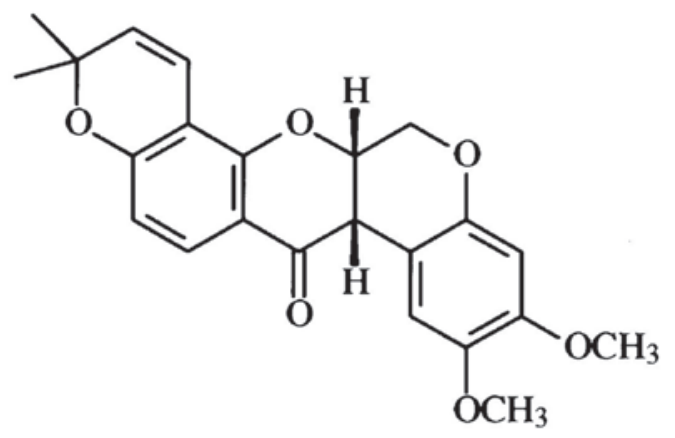

Figure 1. Chemical structure of deguelin.

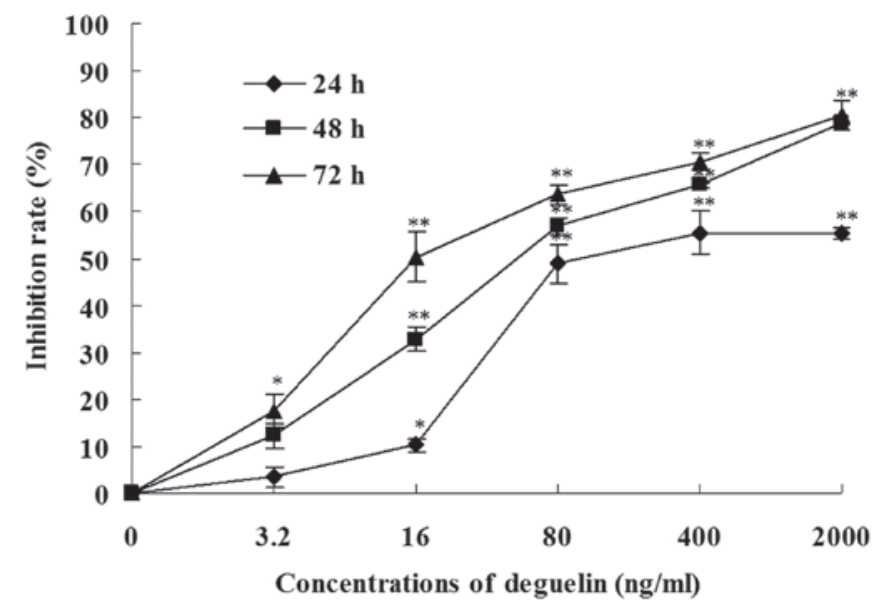

Figure 2. Proliferation inhibitory effect of deguelin on MPC-11 cells Concentration- and time-dependent inhibition of the proliferation of MPC-11 cells by deguelin revealed by MTT assay. Cells were seeded in 96-well-plates and treated with various concentrations of deguelin for 24,48 or $72 \mathrm{~h}$. Data are expressed as mean $\pm \mathrm{SD}$ for at least 5 independent experiments. The asterisk indicates a significant difference between control and deguelin-treated groups ( $\mathrm{P}<0.05$ vs. control group, ${ }^{* *} \mathrm{P}<0.01$ vs. control group).

Statistical analysis. Data are expressed as the mean \pm SD. Statistical comparisons were performed using the ANOVA test. All data were analyzed using SPSS software (SPSS for Windows, ver. 13.0; SPSS, Chicago, IL, USA). P $<0.05$ was considered to indicate a statistically significant result.

\section{Results}

Effects of deguelin on cell proliferation. We tested the antiproliferative effect of deguelin on MPC-11 cells using the MTT assay. The deguelin treatment resulted in a decrease in the cell viability in vitro and the effect was dependent on the dose of deguelin and incubation time (Fig. 2). For example, when MPC-11 cells were treated for $48 \mathrm{~h}$, the inhibition rates of 3.2 and $400 \mathrm{ng} / \mathrm{ml}$ deguelin were $12.2 \pm 2.7$ and $65.5 \pm 0.6 \%$, respectively. When MPC-11 cells were treated with $16 \mathrm{ng} / \mathrm{ml}$ deguelin, the inhibition rate was $10.2 \pm 1.5,32.8 \pm 2.5$ and $50.3 \pm 5.3 \%$ for 24,48 and $72 \mathrm{~h}$, respectively.

Effects of deguelin on cell apoptosis. Agarose gel electrophoresis of deguelin-treated cells revealed a ladder-like pattern of DNA fragments consisting of multiples of $\sim 180-200$ base 

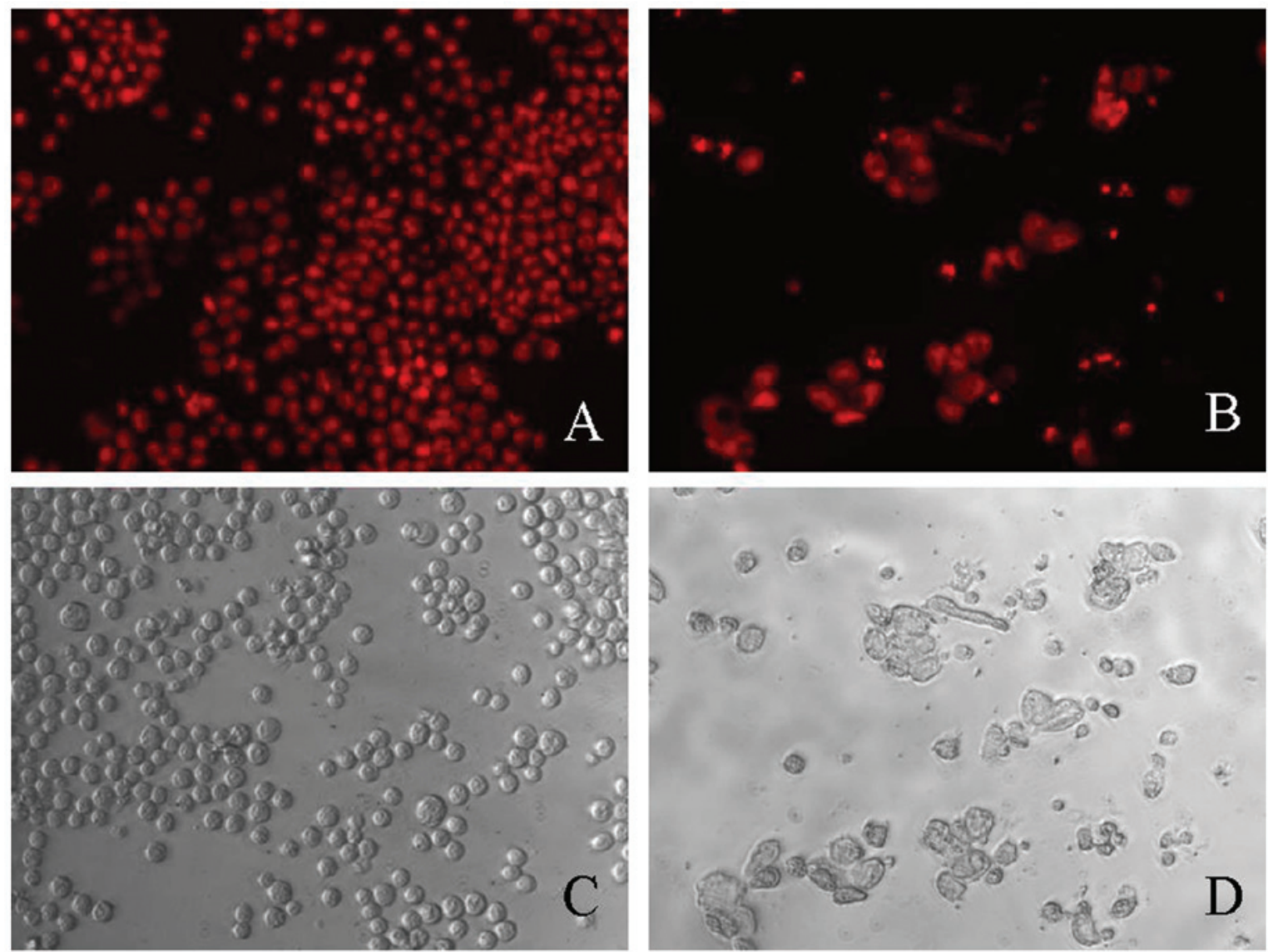

Figure 3. Morphological changes induced by deguelin. (A and B) Fluorescence and (C and D) bright-field microscope images of PI-stained nuclei of MPC-11 cells following incubation with deguelin for $48 \mathrm{~h}$. (A and C) $0 \mathrm{ng} / \mathrm{ml}$ deguelin; (B and D) $100 \mathrm{ng} / \mathrm{ml}$ deguelin. Original magnification, $\mathrm{x} 400$. Apoptotic cells containing condensed and fragmented fluorescent nuclei are visible in deguelin-treated cells, but not in untreated cells. PI, propidium iodide.

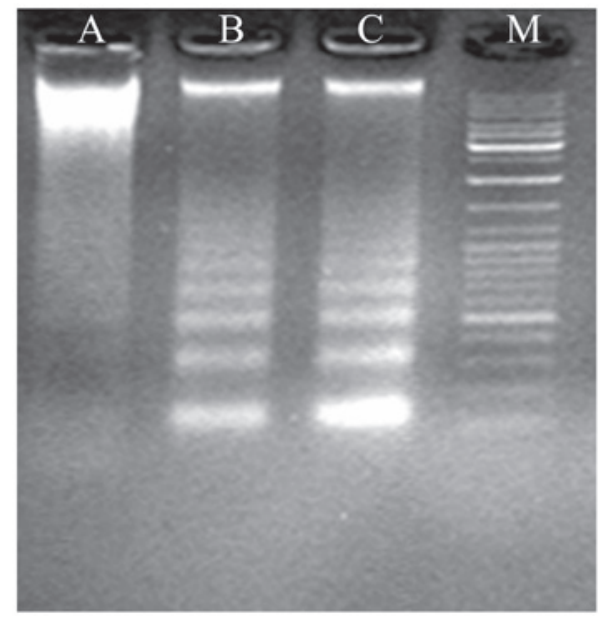

Figure 4. Patterns of DNA following treatment with deguelin. Following exposure to deguelin for $48 \mathrm{~h}$, agarose gel electrophoresis patterns of DNA isolated from MPC-11 cells treated with (A) 0, (B) 50 and (C) $100 \mathrm{ng} / \mathrm{ml} \mathrm{deg-}$ uelin. Ladder-like patterns of DNA fragments are visible in deguelin-treated cells, but not in untreated cells. M, marker.

pairs, consistent with internucleosomal DNA fragmentation (Fig. 3).

Furthermore, fluorescence microscopic examination of PI-stained cells was performed to confirm the apoptosis-inducing effect of deguelin. Treatment with deguelin resulted in morphological changes characteristic of apoptosis, including bright red fluorescent condensed nuclei (intact or fragmented) by fluorescence microscopy of PI-stained nuclei, blebbing, expansion of cell volume, condensation of nuclear chromatin, nuclear fragmentation and apoptotic bodies, and the change was concentration-dependent (Fig. 4).

Mechanistic studies of deguelin effect. To determine whether deguelin was able to modulate the activities of Akt, MPC-11 cells were exposed to increasing concentrations of deguelin in vitro and analyzed for changes in protein levels of Akt. The results revealed that deguelin significantly reduced the level of phosphorylated Akt (p-Akt) in a concentration-dependent manner, but the level of total Akt (t-Akt) was not visibly changed (Fig. 5). It was suggested that deguelin inhibits Akt activity through the inhibition of Akt phosphorylation.

To determine the effects of deguelin on the expression of the $\mathrm{Bcl}-2$ protein group, we examined $\mathrm{Bcl}-2$ and Bax expression in the MPC-11 cells following treatment with deguelin at various concentrations for $48 \mathrm{~h}$. As shown in Fig. 6, inhibition of the expression of Bcl-2 and increase in Bax were confirmed in response to treatment with deguelin. The increase in the Bax/ Bcl-2 ratio has been described in association with the activation of the mitochondrial apoptotic route. The result of the inhibition of Bcl-2 and concomitant increase in Bax expression was in agreement with the result of the apoptosis assay. 


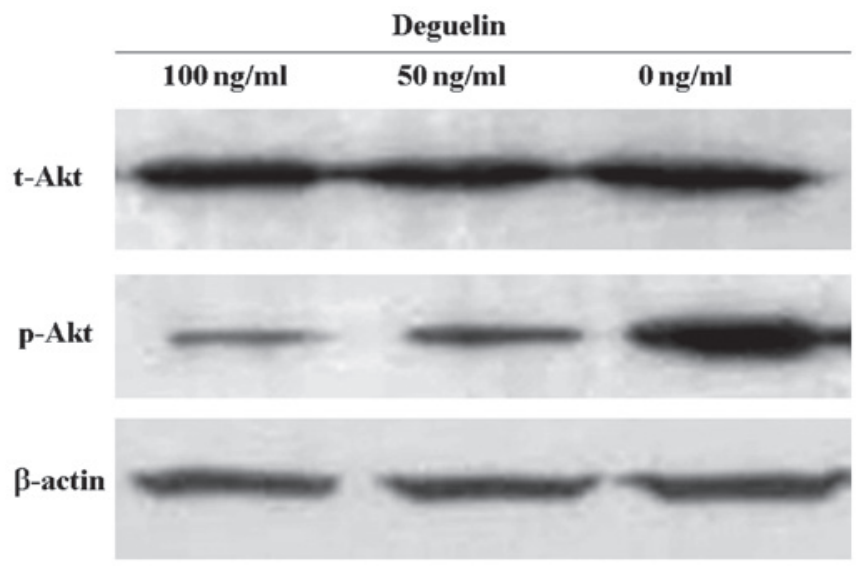

Figure 5. Deguelin inhibits phosphorylation of Akt. MPC-11 cells were incubated with $0-100 \mathrm{ng} / \mathrm{ml}$ deguelin for $48 \mathrm{~h}$. Cells were lysed and analyzed by immunoblotting using antibodies specific for Akt. The phosphorylation of Akt was markedly inhibited by deguelin, whereas the level of total Akt was not influenced.
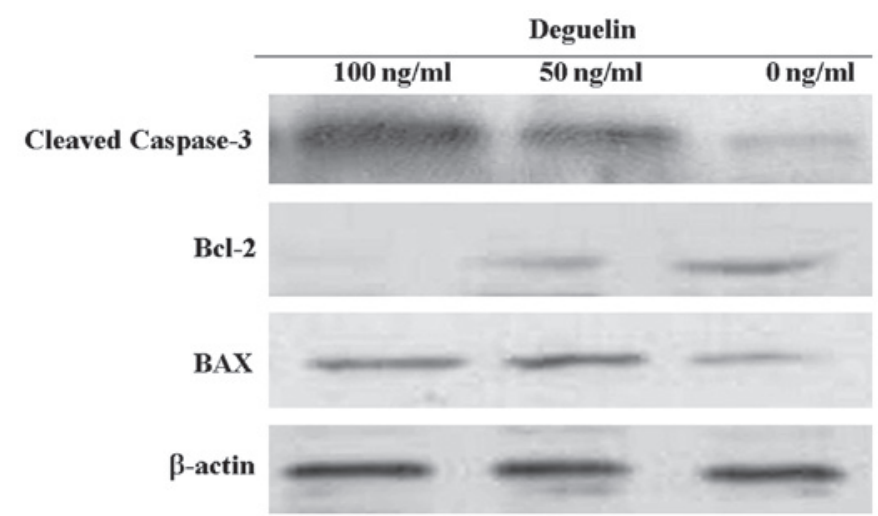

Figure 6. Effects of deguelin on Bcl-2 and Bax expression and activation of caspase-3. MPC-11 cells were treated with deguelin at various concentrations $(0-100 \mathrm{ng} / \mathrm{ml})$ for $48 \mathrm{~h}$ and the expression levels of Bcl-2/Bax and cleaved caspase-3 were analyzed by western blotting. Total protein extracts were subjected to 15\% SDS-PAGE for western blot analysis. Deguelin inhibited Bcl-2 expression in a concentration-dependent manner and simultaneously increased Bax expression. The level of cleaved caspase- 3 was increased by deguelin.

Caspase- 3 is an effector caspase that plays a central role in cell apoptosis. Therefore, we investigated the effect of deguelin on the activation of caspase-3. Treatment MPC-11 cells with deguelin for $48 \mathrm{~h}$ resulted in a concentration-dependent increase of cleaved caspase-3 (Fig. 6).

\section{Discussion}

Multiple myeloma accounts for more than $10 \%$ of all hematological cancers (12) and the average 5-year survival rate is $15-20 \%$, with survival ranging between a few and 10 or more years (1). Novel agents or strategies are needed due to the poor outcome of treatment.

Deguelin is a natural product isolated from plants, which exhibits strong cancer chemopreventive and antitumor activities. However, to the best of our knowledge there are no published data with regard to the effect of deguelin on multiple myeloma.
In the present study, we investigated the antitumor effect of deguelin on the murine myeloma cell line MPC-11 and its possible mechanism in vitro. Our results revealed that deguelin inhibits the proliferation and induces the apoptosis of myeloma cells. Moreover, the cell growth inhibitory effect was associated with a decrease in the phosphorylated levels of Akt, as revealed by immunoblotting.

Firstly, we investigated the cell proliferation inhibition effect of deguelin using the MTT assay. The results revealed that the proliferation of MPC-11 cells was inhibited following exposure to deguelin and that the effect was dose- and time-dependent.

It is well known that the susceptibility of tumor cells to apoptosis is an important determinant of chemotherapy efficacy and that the induction of apoptosis is an important mechanism of antitumor agents, especially natural products (13-16). Therefore, the apoptosis-inducing effect of deguelin was examined. In the present study, DNA fragmentation analysis demonstrated that deguelin induced the apoptosis of MPC-11 cells. The results of fluorescence microscopic examination also revealed features characteristic of apoptosis, confirming the ability of deguelin to induce apoptosis in MPC-11 cells. Consistent with our results, other groups reported that deguelin induced apoptosis in various types of cells, including colon cancer, gastric cancer, leukemia, breast cancer and hepatic cancer cells $(7,8,17-19)$.

The evolutionarily conserved serine/threonine protein kinase Akt is one of the most versatile kinases in the human kinome. Akt is activated by phosphatidylinositol 3-kinase (PI3K), which transmits signals from cytokines, growth factors and oncoproteins to multiple targets, including Akt. Once activated, Akt regulates multiple cellular functions, including survival, proliferation, growth and various aspects of intermediary metabolism. Activated Akt is detectable in numerous types of cancer and has been associated with poor prognosis of cancers, including skin, pancreas, liver, prostate, breast and blood cancers (20-25). Based on these clinical observations, targeting Akt may be a promising strategy against cancer.

In multiple myeloma, Hsu et al reported that the overexpression and activation of Akt played a significant role in malignant cell survival and that the growth of multiple myeloma cells was inhibited if the Akt pathway was paralyzed. The same conclusion was reported independently by Alkan and Izban, further confirming the significant role of Akt in multiple myeloma $(26,27)$.

According to previous studies, deguelin exhibits cancer chemopreventive and anticancer effects through inhibiting the activity of Akt $(5,6)$. In the present study, consistent with others, our data demonstrated that deguelin inhibited the activity of Akt to decrease the survival and growth of MPC-11 cells.

The induction of apoptosis is a common mechanism of numerous anticancer agents and our data showed that deguelin also exhibited apoptosis-inducing activity in MPC-11 cells. To determine the mechanism of the apoptosis induced by deguelin, the proteins involved in apoptosis were analyzed by western blotting. Caspase-3 is the key molecule in cellular apoptosis and the activation of caspase- 3 is often considered to be the point of no return in the apoptotic signaling cascade. In the present study, we found that caspase- 3 was activated following 
exposure to deguelin. To further determine the pathway of apoptosis induced by deguelin, we analyzed the upstream regulators of caspase-3. $\mathrm{Bcl}-2$ family proteins are central regulators of the apoptosis pathway, which either suppress or promote changes in mitochondrial membrane permeability required for the release of cytochrome c $(28,29)$. Of the Bcl-2 family, Bcl-2 and Bax have been identified as major regulators in controling the release of mitochondrial cytochrome c (30). Bcl-2 blocks cytochrome c efflux, whereas Bax enhances the release of cytochrome $\mathrm{c}$ and induces apoptosis. The overexpression of antiapoptotic Bcl-2 probably occurs in more than half of all cancers (31). Our results revealed that treatment with deguelin induced the downregulation of Bcl-2 and upregulation of Bax in MPC-11 cells in a dose-dependent manner. It is suggested that deguelin induced the apoptosis of MPC-11 cells via an intrinsic mechanism, which is regulated via the inhibition of Bcl-2 and a concomitant stimulation of Bax protein expression.

We conclude that deguelin is able to inhibit cell proliferation and induce apoptosis in MPC-11 cells in vitro. We demonstrated that at least two mechanisms are involved: inhibition of the activity of Akt/ERK and modulation of the Bcl-2/Bax ratio to activate caspase-3. The ability of deguelin to mediate these responses in myeloma cells makes it a potentially effective therapeutic agent against multiple myeloma and warrants further investigation.

\section{Acknowledgements}

This study was financially supported by the Technology Project of Changzhou Social Development (CS20102016) and the Natural Science Funds for Young Teacher of Soochow University (Q3124943).

\section{References}

1. Becker N: Epidemiology of multiple myeloma. Recent Results Cancer Res 183: 25-35, 2011

2. Palumbo A and Anderson K: Multiple myeloma. N Engl J Med 364: 1046-1060, 2011.

3. Fang N and Casida JE: Anticancer action of cubé insecticide: correlation for rotenoid constituents between inhibition of NADH: ubiquinone oxidoreductase and induced ornithine decarboxylase activities. Proc Natl Acad Sci USA 95: 3380-3384, 1998.

4. Gerhäuser C, Mar W, Lee SK, et al: Rotenoids mediate potent cancer chemopreventive activity through transcriptional regulation of ornithine decarboxylase. Nat Med 1: 260-266, 1995

5. Chun KH, Kosmeder JW II, Sun S, et al: Effects of deguelin on the phosphatidylinositol 3-kinase/Akt pathway and apoptosis in premalignant human bronchial epithelial cells. J Natl Cancer Inst 95: 291-302, 2003.

6. Lee HY, Oh SH, Woo JK, et al: Chemopreventive effects of deguelin, a novel Akt inhibitor, on tobacco-induced lung tumorigenesis. J Natl Cancer Inst 97: 1695-1699, 2005.

7. Lee JH, Lee DH, Lee HS, Choi JS, Kim KW and Hong SS: Deguelin inhibits human hepatocellular carcinoma by antiangiogenesis and apoptosis. Oncol Rep 20: 129-134, 2008.

8. Murillo G, Salti GI, Kosmeder JW II, Pezzuto JM and Mehta RG Deguelin inhibits the growth of colon cancer cells through the induction of apoptosis and cell cycle arrest. Eur J Cancer 38 2446-2454, 2002.
9. Udeani GO, Gerhauser C, Thomas CF, et al: Cancer chemopreventive activity mediated by deguelin, a naturally occurring rotenoid. Cancer Res 57: 3424-3428, 1997.

10. Ling YH, Priebe W and Perez-Soler R: Apoptosis induced by anthracycline antibiotics in P388 parent and multidrug-resistant cells. Cancer Res 53: 1845-1852, 1993.

11. Wei YQ, Zhao X, Kariya Y, Fukata H, Teshigawara K and Uchida A: Induction of apoptosis by quercetin: involvement of heat shock protein. Cancer Res 54: 4952-4957, 1994.

12. Kyle RA and Rajkumar SV: Multiple myeloma. N Engl J Med 351: 1860-1873, 2004.

13. Kaufmann SH and Earnshaw WC: Induction of apoptosis by cancer chemotherapy. Exp Cell Res 256: 42-49, 2000.

14. Ciucci A, Gianferretti P, Piva R, et al: Induction of apoptosis in estrogen receptor-negative breast cancer cells by natural and synthetic cyclopentenones: role of the IkappaB kinase/nuclear factor-kappaB pathway. Mol Pharmacol 70: 1812-1821, 2006.

15. Fan E, Jiang S, Zhang L and Bai Y: Molecular mechanism of apoptosis induction by resveratrol, a natural cancer chemopreventive agent. Int J Vitam Nutr Res 78: 3-8, 2008.

16. Wolf I, O'Kelly J, Wakimoto N, et al: Honokiol, a natural biphenyl, inhibits in vitro and in vivo growth of breast cancer through induction of apoptosis and cell cycle arrest. Int J Oncol 30: 1529-1537, 2007

17. Geeraerts B, Vanhoecke B, Vanden Berghe W, Philippé J, Offner F and Deforce D: Deguelin inhibits expression of IkappaBalpha protein and induces apoptosis of B-CLL cells in vitro. Leukemia 21: 1610-1618, 2007.

18. Lee H, Lee JH, Jung KH and Hong SS: Deguelin promotes apoptosis and inhibits angiogenesis of gastric cancer. Oncol Rep 24: 957-963, 2010.

19. Peng XH, Karna P, O'Regan RM, et al: Down-regulation of inhibitor of apoptosis proteins by deguelin selectively induces apoptosis in breast cancer cells. Mol Pharmacol 71: 101-111, 2007.

20. Dai DL, Martinka M and Li G: Prognostic significance of activated Akt expression in melanoma: a clinicopathologic study of 292 cases. J Clin Oncol 23: 1473-1482, 2005.

21. Kreisberg JI, Malik SN, Prihoda TJ, et al: Phosphorylation of Akt (Ser473) is an excellent predictor of poor clinical outcome in prostate cancer. Cancer Res 64: 5232-5236, 2004.

22. LoPiccolo J, Granville CA, Gills JJ and Dennis PA: Targeting Akt in cancer therapy. Anticancer Drugs 18: 861-874, 2007.

23. Perez-Tenorio G and Stal O: Activation of AKT/PKB in breast cancer predicts a worse outcome among endocrine treated patients. Br J Cancer 86: 540-545, 2002.

24. Schlieman MG, Fahy BN, Ramsamooj R, Beckett L and Bold RJ: Incidence, mechanism and prognostic value of activated AKT in pancreas cancer. Br J Cancer 89: 2110-2115, 2003.

25. Terakawa N, Kanamori Y and Yoshida S: Loss of PTEN expression followed by Akt phosphorylation is a poor prognostic factor for patients with endometrial cancer. Endocr Relat Cancer 10: 203-208, 2003.

26. Alkan S and Izban KF: Immunohistochemical localization of phosphorylated AKT in multiple myeloma. Blood 99: 2278-2279, 2002.

27. Hsu J, Shi Y, Krajewski S, et al: The AKT kinase is activated in multiple myeloma tumor cells. Blood 98: 2853-2855, 2001.

28. Green DR and Reed JC: Mitochondria and apoptosis. Science 281: 1309-1312, 1998.

29. Gross A, McDonnell JM and Korsmeyer SJ: BCL-2 family members and the mitochondria in apoptosis. Genes Dev 13: 1899-1911, 1999.

30. Ghribi O, Herman MM, Spaulding NK and Savory J: Lithium inhibits aluminum-induced apoptosis in rabbit hippocampus, by preventing cytochrome $\mathrm{c}$ translocation, $\mathrm{Bcl}-2$ decrease, Bax elevation and caspase-3 activation. J Neurochem 82: 137-145, 2002.

31. Amundson SA, Myers TG, Scudiero D, Kitada S, Reed JC and Fornace AJ Jr: An informatics approach identifying markers of chemosensitivity in human cancer cell lines. Cancer Res 60: $6101-6110,2000$ 